Indian J Anim Health (2021), 60(2): 145-159

\title{
Advanced assisted reproductive technology in cattle: OPU-IVF review
}

\author{
D. Sarkar ${ }^{1 *}$, A. Teja ${ }^{2}$, K. Debbarma ${ }^{1}$, M. Karunakaran ${ }^{1}$, A. Debbarma ${ }^{1}$, T. K. Mohanty ${ }^{3}$, \\ Suryaprakash $^{3}$, P. Kumar ${ }^{3}$, M. Rahman ${ }^{4}$
}

${ }^{1}$ Department of Animal Reproduction Gynaecology and Obstetrics, ERS of ICAR-National Dairy Research Institute (NDRI), Kalyani - 741 235, Nadia, West Bengal, India; ${ }^{2}$ Department of Animal Reproduction Gynaecology and Obstetrics, SRS of ICAR - National Dairy Research Institute (NDRI), Bengaluru-560 030, Karnataka, India; ${ }^{3}$ Department of Animal Reproduction Gynaecology and Obstetrics, ICAR-National Dairy Research Institute (NDRI), Karnal - 132 001, Haryana, India; ${ }^{4}$ Department of Animal Genetics and Breeding, ERS of ICAR-National Dairy Research Institute (NDRI), Kalyani - 741 235, Nadia, West Bengal, India

\begin{abstract}
India ranked $1^{\text {st }}$ in cow and buffalo population in the world with annual production of $187.75 \mathrm{MT}$ of milk and 8.11 MT of meat, livestock contributes $4.1 \%$ in of total GDP. Even though, production is inadequate to fulfill the nutritional demands of population of the country. To generate bulk quantity of food products to fulfill the demands required to adopt new technologies or refining of the technologies, which in turn can increase in production and here, assisted reproductive technology (ART) can play a major role including In vitro fertilization (IVF) technology. In world, 6,66,000 embryos produced by IVF in 2016 and in Brazil IVP increased by $184.0 \%$ between 2005 and 2016 . Live offspring of 25 species already been achieved though embryo transfer technology. Initially, in vitro embryo production (IVEP), the oocytes were collected from the slaughterhouse ovaries and at present, oocytes are being collected from the live animal by using OPU methodology. To maintain optimum quality of embryo production and production rate clean room preparations is radically important. Polluted air and volatile organic compounds are contributing in poor in vitro embryo production. IVF is become a regular tool to produce embryos for different purpose including research throughout the world. This technology needs further refinement and here we reviewed about Ovum pick up - In vitro fertilization (OPU- IVF) technique for cattle, clean room methodologies and pointed out the major considerations that can definitely help researchers.
\end{abstract}

Key words: Assisted reproductive technology, In vitro Fertilization, Ovum pick up, Volatile organic compounds

\section{Introduction}

India ranked $1^{\text {st }}$ in cow and buffalo population in the world. India produces 187.75 MT of milk and 8.11 MT of meat. Livestock contributes $4.1 \%$ of the total GDP in India, per capita availability of milk in India is $394 \mathrm{~g} /$ day (BAHS, 2019). Even though, production is inadequate to fulfill the nutritional demands of population of the country. To generate bulk quantity of food products to fulfill the demands required to adopt new technologies or refining of the technologies, which in turn can increase in production. Reproduction is key area to produce livestock with desirable traits and here, assisted reproductive technology (ART) can play a major role including In vitro fertilization (IVF) technology. In the year 2016, total $6,66,000$ number of embryos produced by IVF worldwide. Alone in Brazil the in vitro embryo production increased by $184.0 \%$ between 2005 and 2016 while in vivo derived embryos decreased by $73.7 \%$. Till now, by using embryo transfer technology in 25 species live offspring already been acquired (Verma et al., 2012; Abdullah et al., 2018; Reuben et al., 2018). It represents there are vast opportunities to do further research to develop highly productive animals in high number in a short time span. Here, we have discussed the historical development of the IVF technology, production

"Corresponding Author, E Mail: sarkardebajyoti@ymail.com 
rates constrains, future scope of this IVF and OPU-IVF technology.

\section{Historical background of assisted reproductive technologies}

The first generation assisted reproductive tool is artificial insemination. Following that there was further development of ART's namely super ovulation, embryo transfer technology (ETT), In Vitro fertilization (IVF), ovum pick up technique (OPU), combination of OPU-IVF, pregnancy diagnosis by ultrasonography. Now, at the present genomic selection by using DNA analysis can be recognized as ART of 21st century (Moore and Hasler, 2017; Purohit, 2018).

In 1976, "assisted fertilization" experiment was done by micro injection of Hamster oocyte with human sperm pioneered by Uehera and Yanagimachi (1976). Around the same time, on 1780 first artificial insemination had done by L. Spallanzani in Beagle dog and produced three pups. Although in India, first artificial insemination was done in cattle by S. Kumaran, 1939 at Mysore cattle palace. Sequentially the first super ovulation technique reported by Casida et al., 1943 and first embryo transfer was done by Willett, 1951 and produced calf.
In India, first embryo transfer was done at National Institute of Immunology, New Delhi, 1987. The in vitro fertilization (IVF) techniques yield first calf, "VIRGIL" by Brackett et al., 1982. In India, first buffalo calf "PRATHAM" produced by using this technology in National Dairy Research Institute, Karnal, 1990 (Madan et al., 1991; Nain et al., 2006) and recently produced first calf of Tharparker breed by Dr. Zawar, Pune on $5^{\text {th }}$ Sept. 2017 (Purohit, 2018). Most advance technique of oocyte collection from the live animal i.e., first ovum pick up technique (OPU) was introduced by Callesen et al.1987, performed in Bovine. In India, OPU followed by IVF and development of embryo upto Blastocyst-reported by Verma, 2005, in Bovine. The first OPU- IVF in aged Sahiwal cattle done at National Dairy Research Institute, Karnal, 2012 and produce Sahiwal calf "HOLI" (Saini et al., 2015; Moore and Hasler, 2017; Purohit, 2018). Even though, in India this technological development confined within reputed institutes, here can see in Brazil (exemplary country) where they utilised this technology for the development of livestock and getting successful increasing production and productivity.

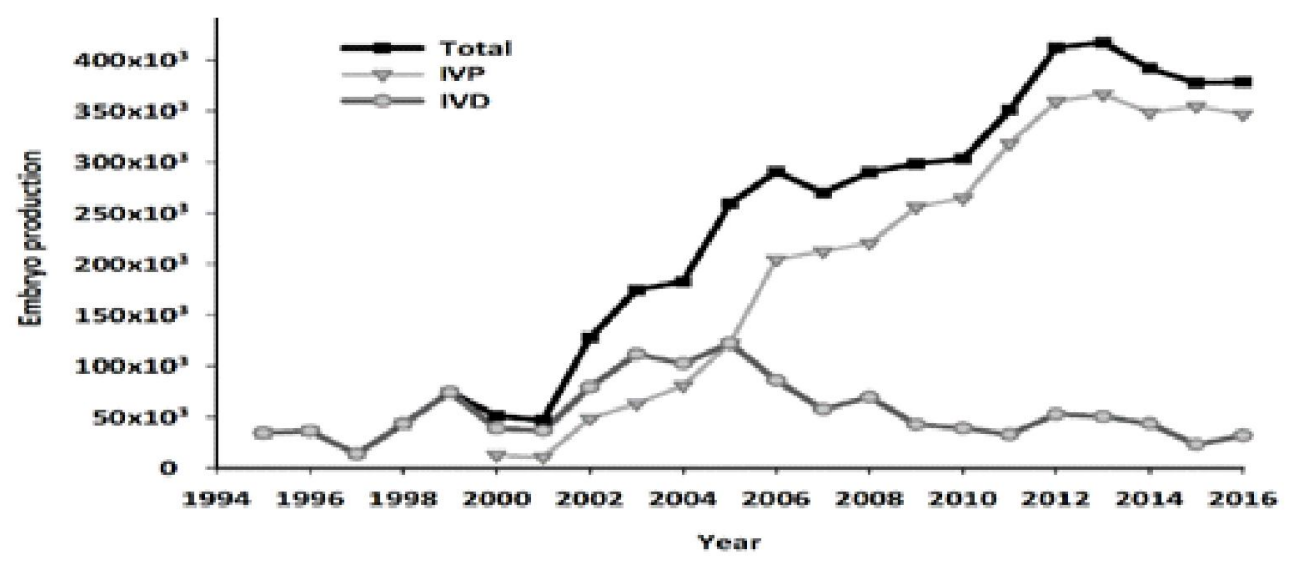

Growth of IVP Technology in Brazil from 1995 to 2016

Fig. 1. The pattern of production of bovine embryos in Brazil during 1995 to 2016 . Total indicates combination of in vivo and in vitro embryos; IVP- In vitro production of embryo, OPU/ IVF; IVD- In vivo derived embryo produced by using super ovulation followed by embryo collection; observed increases trend of IVP due to modification and development of superior culture medium and increased conception rate followed by IVF (Reuben et al., 2018) 


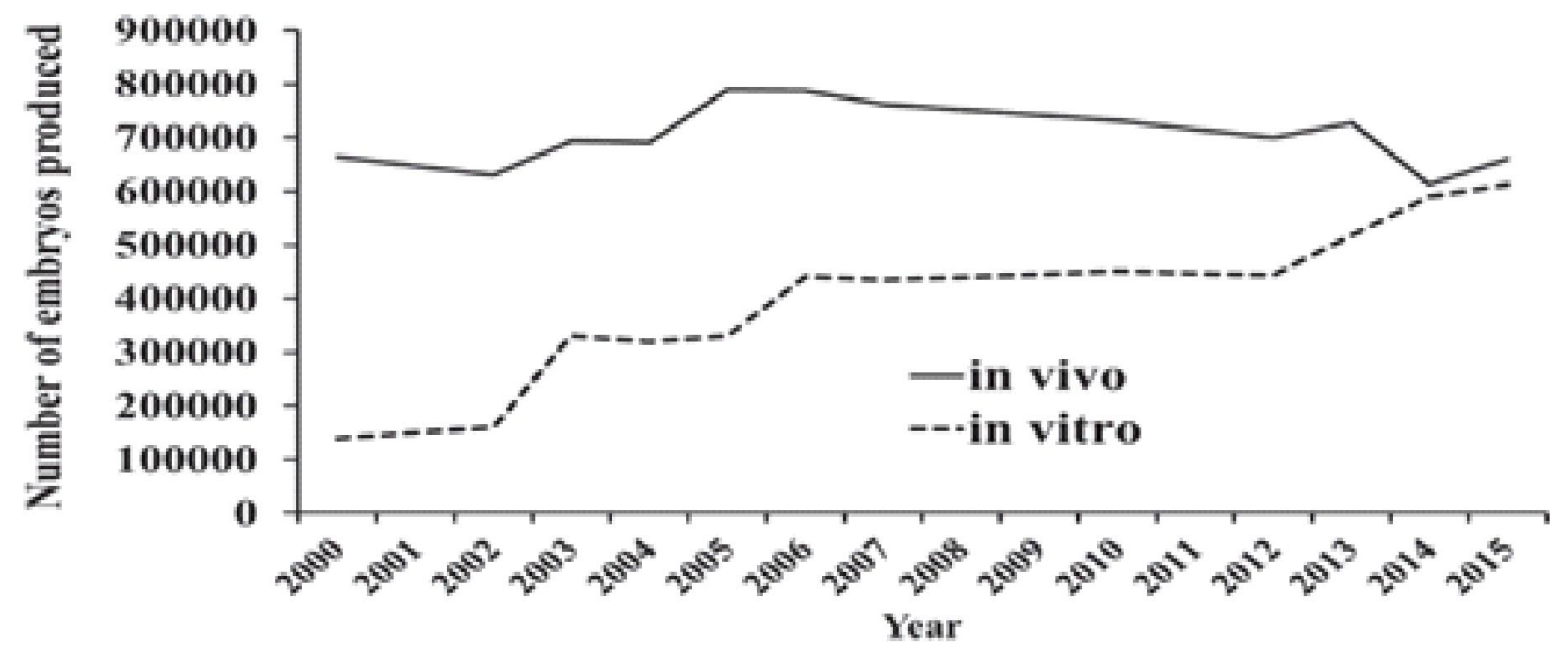

Worldwide scenario upon IVD and IVF

Fig. 2. Continuous increasing trend in IVP embryos compared to IVD since year 2000 onwards; IETS (Moore and Hasler, 2017)

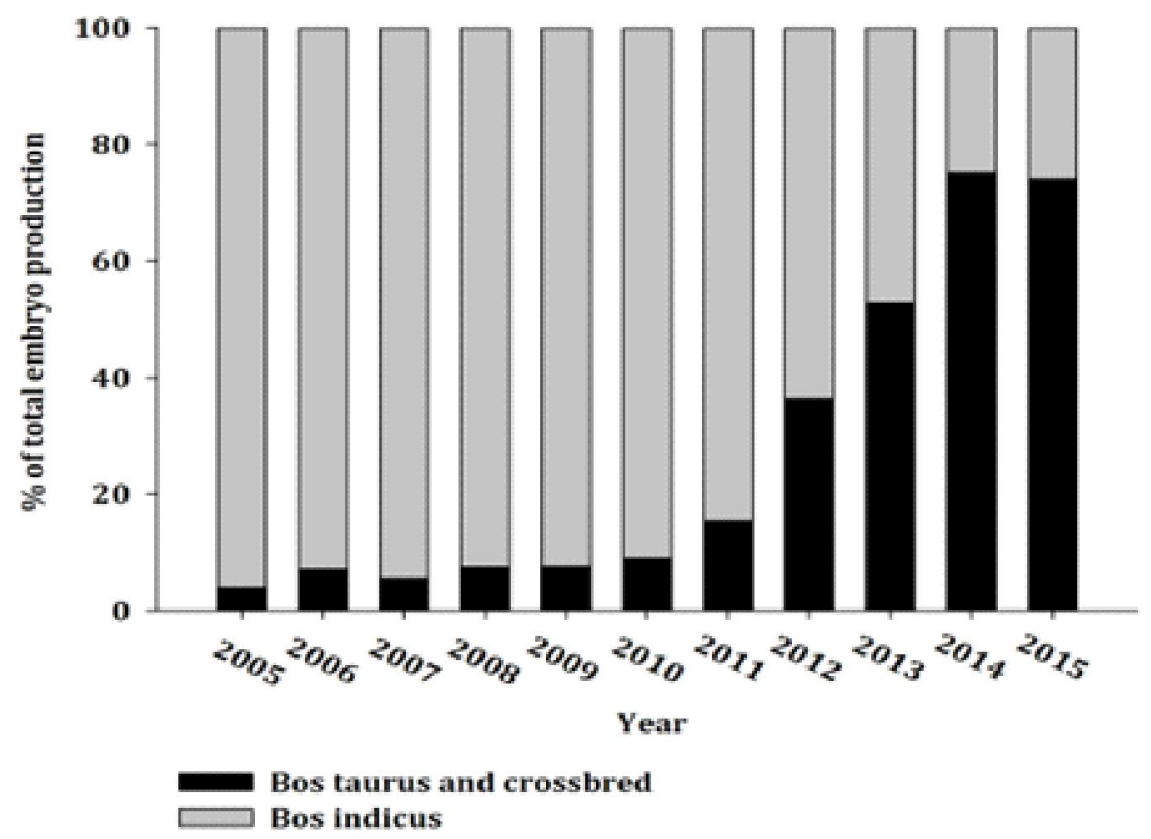

Trend (in percentage) of Brazilian embryo production in Bos taurus and Bos indicus

Fig. 3. Brazilian embryo production (in percentage) in two bovine species from 2005 to 2015 , majorly the $B$. taurus animals are using for production of embryos compared to $B$. indicus (Viana et al., 2017) 


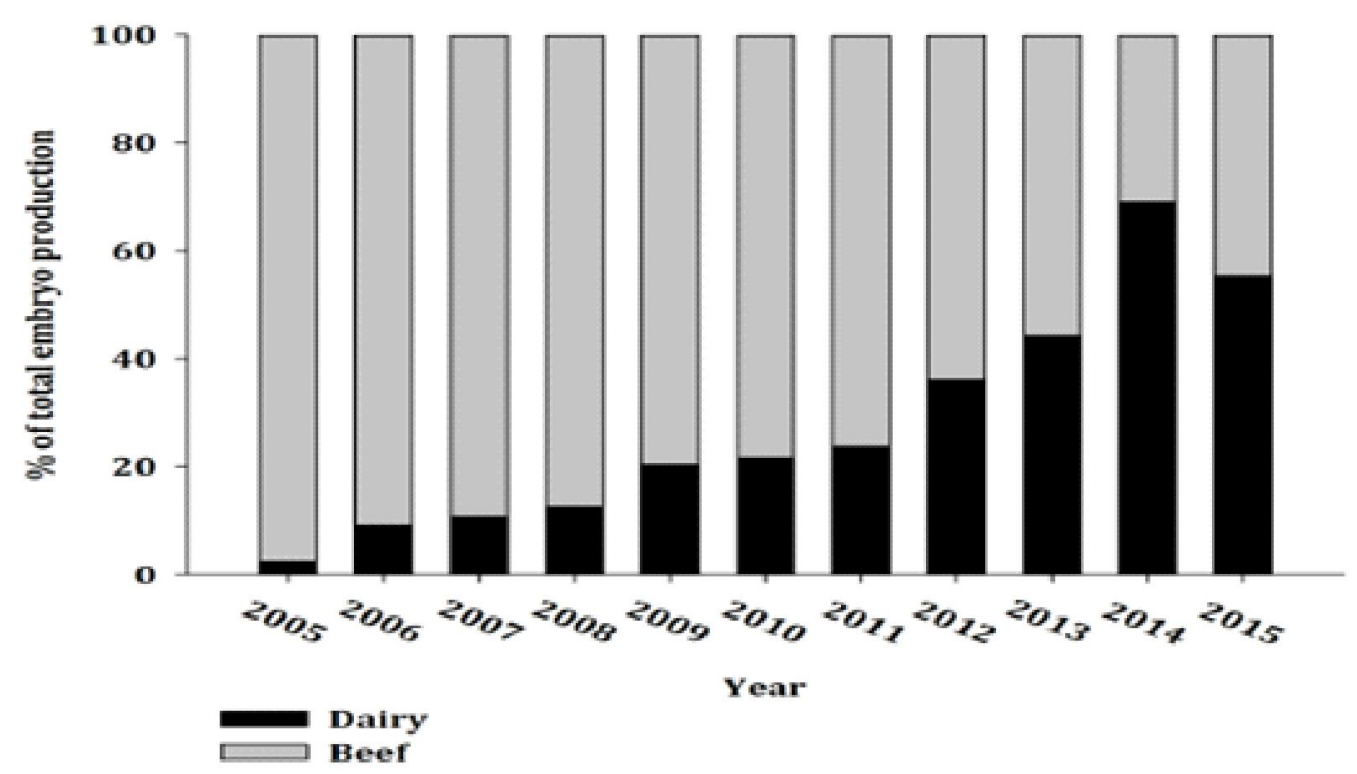

Fig. 4. Brazilian embryo production (in percentage) in dairy and beef breeds from 2005 to 2015 (Viana et al., 2017)

\section{In Vitro embryo production}

In vitro embryo production (IVEP) is the combination of three major steps: a) in vitro maturation (IVM) of collected oocytes either from slaughterhouse ovaries or from live animal by OPU technique from live animals, b) In vitro fertilization (IVF), where matured oocytes are fertilized by the spermatozoa from sexed semen or semen from elite bull and c) In vitro culture (IVC) procedure, the fertilized oocytes are being cultured in appropriate media where they are nourished to develop up to the blastocyst stages. Generally, the time duration of culture is 7 days for cow. As per species, the culture duration varies. The appropriate timing of transfer of embryo maximizes the pregnancy rate in the recipient animal.

Oocyte collection: Previously, in the in vitro embryo production programmes, embryos were developed from the procured ovaries from slaughterhouse (Lu and Polge, 1992; Sinclair et al., 1995; Kuwayama et al., 1996; Lazzari and Galli, 1996). Currently due to the technological improvement, the oocytes are collected from the ovaries of elite live animal by using OPU method. This enables repeated oocyte recovery from the animal within a gap of very short period and yield more embryos from the elite animal (Galli and Lazzari, 2008). This technique is using in many countries for production of IVEP. This technique is being used for collection of oocytes from endangered species to conserve the genetic resources in much faster way (Hafez, 2015).

Grading of oocyte: Grading of oocytes can be done based on number of cumulus-oocyte complex (COC) layers, expansion of cumulus cell, cytoplasmic appearance in terms-colour, consistency and integrity of zona pellucida (Cavalieria et al., 2018).

In-vitro maturation (IVM): IVM process requires certain in vitro environment to develop the embryo and these requirements are summarized as $38.5^{\circ} \mathrm{C}$ temperature, $5 \% \mathrm{CO}_{2}$ in air, $90-95 \%$ humidity for 22-24 hours kept in 35 drops of $75 \mu \mathrm{L}$ of maturation medium. This media contains TCM 199, earls salt, glutamine, sodium bicarbonate, $10 \%$ fetal calf serum, 0.5 $\mu \mathrm{g} / \mathrm{mL}$ FSH, $22 \mu \mathrm{g} / \mathrm{mL}$ of pyruvate, $50 \mu \mathrm{g} / \mathrm{mL}$ of gentamicin, $50 \mu \mathrm{g} / \mathrm{mL}$ of $\mathrm{LH}, 1 \mu \mathrm{g} / \mathrm{mL}$ estradiol (Chowdhury et al., 2019).

Sperm selection: Semen straws are thawing at 
$38.5^{\circ} \mathrm{C}$ for $1 \mathrm{~min}$ and collected semen in DPBS medium followed by centrifugation at $750-\mathrm{x} \mathrm{g}$ for $5 \mathrm{~min}$ at room temperature. After the centrifugation, the semen sample should resuspended in the IVF medium containing tyrode lactate solution with bovine serum albumin (BSA) $6 \mathrm{mg} / \mathrm{mL}$, sodium pyruvate 22 $\mathrm{mg} / \mathrm{mL}$, penicillin $100 \mathrm{IU} / \mathrm{mL}$, streptomycin 0.1 $\mathrm{mg} / \mathrm{mL}$, supplemented with heparin $20 \mathrm{mg} / \mathrm{mL}$. Followed by incubated at $38.5^{\circ} \mathrm{C}$ in a humidified atmosphere of $5 \% \mathrm{CO}_{2}$ in air for $15 \mathrm{~min}$ to facilitate capacitation. Final concentration of semen sample is $1 \times 10^{6} \mathrm{sperm} / \mathrm{mL}$ in IVF medium (De et al., 2011; Ayman et al., 2017; Chowdhury et al., 2019).

Sperm selection for sexed embryo: In recent development, scientists are trying to sexing of semen by using the monoclonal antibody. It is reported that sex sorting has a negative effect on sperm quality. It altered the pattern of sperm motility; reduce the period of cell viability (Chowdhury et al., 2019). Researcher has approached a new technique to produce preselected embryo by using a monoclonal antibody which been developed against bull sperm epitopes. This antibody separates the $\mathrm{X}$ and $\mathrm{Y}$ sperm in a simple and easy process and provides preselected embryo production. The mechanism of action of this method involves immobilization of the male spermatozoa and the XX spermatozoa will bind with the oolemma of oocyte followed by fertilization. They found that there was no significant differences $(\mathrm{P}>0.05)$ in the percentage of presumptive zygotes production between the control and the $\mathrm{X}$-sperm sorted group, but there was a difference in early cleavage embryos with $81.2 \pm 1.4,78.3 \pm 1.0$ and $66.7 \pm 1.1 \%$ for the control, X-sperm sorted, and Y-sperm sorted groups, respectively.

Chowdhury et al. (2019) also found that there were significant differences $(\mathrm{P}<0.05)$ in the percentage of embryo development up to the blastocyst stage (Day 7) 34.8 $\pm 1.0,32.1 \pm 0.8$, and $23.7 \pm 1.0 \%$ in the control, $\mathrm{X}$-sperm sorted, and Y-sp sperm sorted groups, respectively. The author also reported that by analyzing the gene expression (B-SRY F2 and B-SRY R2) of in vitro produced embryos that the detection accuracy of female embryos was $81.0 \%$ and for the male embryos $72.5 \%$.

Chowdhury et al. (2019) concluded that no differences in cleavage and blastocyst developmental rates with use of sperm with the $\mathrm{X}$ chromosome and sperm unsorted sperm with $\mathrm{X}$ or $\mathrm{Y}$ chromosomes (control). This cell sorting technique is less time consuming and produces less stress on sperm cells compared to current method of sperm sexing. This technique can be useful in sperm selection in case of IVEP technique.

Other method of sperm selection is swimup method. Application of this method yields more male embryos (58\%) and compared to female embryos (Wolf et al., 2008). It is due morphological character of $\mathrm{Y}$-chromosome bearing sperm i.e., due to lighter, smaller and faster compared to the X-chromosome bearing sperm (McEvoy, 1992; Johnson, 2000). However, with $67.5 \%$ continuous percoll density gradient centrifugation for $10 \mathrm{~min}$ yield more amount of female sperm (Wolf et al., 2008), and female embryo following the in vitro fertilization. There still a scope to use larger volume of percoll gradient and increasing in centrifugation can induce more sex sorted sperm for production of IVF embryo.

In-vitro fertilization: Matured COCs are kept in 4-well dishes for fertilization. Each well contains $500 \mathrm{~mL}$ of IVF medium and spermatozoa. These 4-well dishes are incubated at $5 \% \mathrm{CO}_{2}$ in air $38.5^{\circ} \mathrm{C}$ for $18-20 \mathrm{hr}$ (Rosenkrans et al., 1993; Ayman et al., 2017).

In-vitro culture: This process carried out at $38.5^{\circ} \mathrm{C}$ temp, $5 \% \mathrm{CO}_{2}$ in air and $90-95 \%$ humidity. The culture kept in 4-well dishes, which contain $500 \mathrm{~mL} \mathrm{CR} 1$-aa medium. This media contains $3 \mathrm{mg} / \mathrm{mL}$ BSA, $310 \mathrm{mg} / \mathrm{mL}$ glutathione for initial 3 days, $44 \mathrm{mg} / \mathrm{mL}$ sodium pyruvate, $100 \mathrm{IU} / \mathrm{mL}$ penicillin, $14.6 \mathrm{mg} / \mathrm{mL}$ glutamine, $0.1 \mathrm{mg} / \mathrm{mL}$ streptomycin, $10 \%$ fetal calf serum (FCS) after 3 days of culture (Rosenkrans et al., 1993; Ayman et al., 2017). 


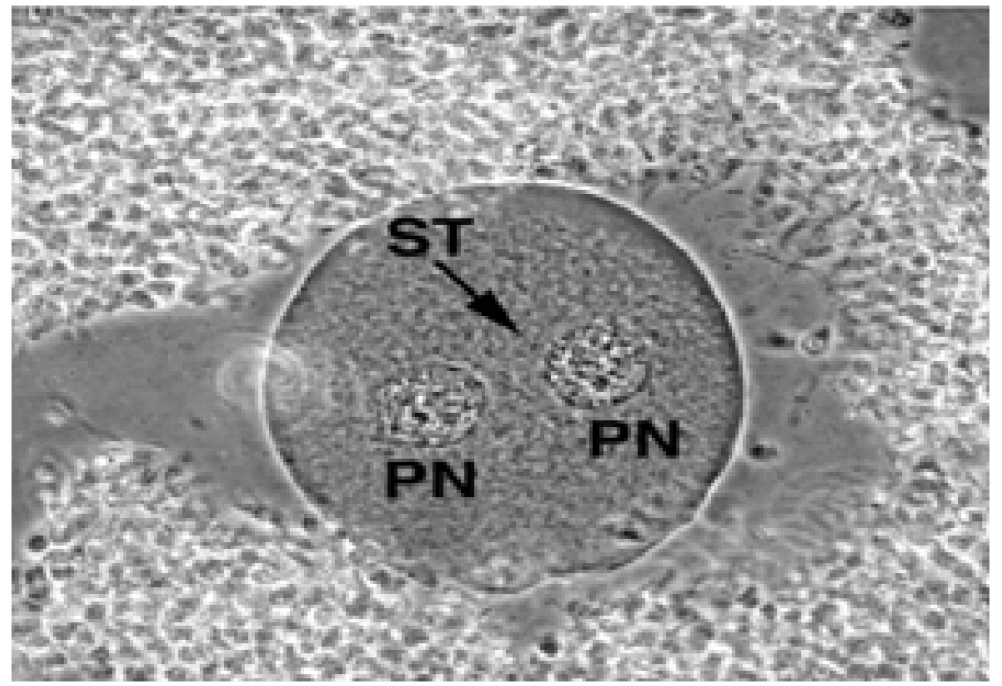

Fig. 5. One of the embryos produced after using heparin for capacitation (Parrish et al., 1986)

\section{Effect of light exposure upon embryo during ART}

IVF lab procedures, embryos exposed to radiation energy from light. This produces stress upon its biological systems. The blue light (400$500 \mathrm{~nm}$ ) is harmful than longer wave length visible light due to generation of $\mathrm{H}_{2} \mathrm{O}_{2}$, hydroxyl radicals production, damaging the amino acids, phospholipids, nucleotides, organic acids and ultimately changes in the respiratory chain leading to impaired mitochondrial function and lastly cellular damage (Aggarwal et al., 1978; Hirao et al., 1978; Ramadan-Talib and Prebble, 1978; Halliwell et al., 1989; Umaoka et al., 1992; Squirrell et al., 1999; Hockberger et al., 1999). The damages can reduce by mounting filters on the inspection microscopes. Therefore, without hampering the visualisation can exclude the radiation energy within the range of the 400-500 $\mathrm{nm}$. On the other hand, reducing the exposure time as well as narrowing the illuminated area by just focusing upon the embryo can reduce the damage (Ottosen and Hindkjaer, 2007).

\section{IVF room}

The laboratory room should have smooth, non-porous walls, impervious unbroken surfaces, corners with rounded edges and easy to clean, no sliding doors, sinks and drains. Ducts and pipes can be insulated internally i.e., hidden between wall panels or externally (covered within an alcove) to prevent dust accumulation. As the most of the laboratory located in cities and towns, "clean room technology" can easily controlled the entry of particles and contaminants in significantly manner. Clean room cells (CRC) that are standalone prefabricated laboratory can provide instant clean room environment within preexisting buildings or in locations with poor overall air quality or in the absence of local materials and expertise. In this kind of rooms, hermetically sealed doors and windows are used. Adjacent rooms are interconnected by single door. Positive air pressure achieved by using high efficiency particle air (HEPA) filters which can highly filtrate the air. Also can be use central air handling system that includes activated carbon pre-filters, chemical filters and photo catalytic conversion that damage volatile compounds, bacteria and moulds. Maintenance of HEPA filter is crucial to maintain standard equipment status, safeguards against drop in air quality (Forman et al., 2004).

Air in urban areas contains high levels carbon monoxide, nitrous oxide, sulphur 
dioxide, heavy metals and in addition, inside the lab contains volatile organic compounds (VOCs), dusts from construction materials, MDF (medium-density fiberboard), PVC flooring, paints, adhesives, chemicals like cleaning fluids, floor waxes, cosmetics and cigarette smoke which produce the phenomenon "sick building syndrome" (Takigawa et al., 2010). The poor air quality within an IVF lab has negative effect upon on fertilisation and embryo development (Boone et al., 1997; Dean, 2015). VOC levels can be monitored either by electronically or organic chemical sensors. The furniture and workbenches has to make up of stainless to reduce VOC emission. Highest VOC levels were acetone can reach up to a level of 15.5 ppm (Martine and Verheyen, 2016).

Cohen et al. (1997) has shown that inside the IVF lab sometimes-high levels of aldehydes, noxious compounds, VOCs are higher than outside air. The air contaminants can settle on work surfaces, dissolve in aqueous or lipophilic oil solutions, embryo culture medium ultimately harming the embryos. Reactive aldehyde present in air which can arrest mouse embryos at the 8-cell stage at concentration of 2.1 parts per million (ppm) and live birth rate was reduced at a concentration of $0.58 \mathrm{ppm}$ (Hall et al., 1998; Destaillats et al., 2002; Dean, 2015). In a study in Japan upon sick building syndrome they found that chemical like aldehydes are the responsible for the SBS condition among the human (Takigawa, 2010).

In instruments, the copper pipes are prone to oxidation should not be used for transportation of medical grade gasses from cylinder to incubator and best to be replace with inert stainless steel tubes. Compressed gas like medical grade $\mathrm{N}_{2}$ and $\mathrm{CO}_{2}$ used for embryo production may contains harmful compounds like benzene, isopropanol and pentane, these should be eliminate before entering the incubators (Hall et al., 1998; Mayer et al., 1999).

Staff is among one of the biggest contaminants in a clean environment. Exhaled air from smokers contains residual tobacco particles ( 0.5 and 2 micron in size) that can remain indefinitely in the air or settle on surfaces and walls. Therefore, smokers should be discouraged from smoking within the working day. Beards long than 3-4 mm should be covered. "Air shower" before entering the laboratories acts as physical barrier which can reduce particle contamination. Polyester garments are most suitable for IVF laboratory because it does not shred fibres; carry less residual traces of laundry detergent (Martine and Verheyen, 2016). A moving person sheds 1 million particles $\geq 0.5 \mu \mathrm{m}$ per minute, and a walking person sheds over 5 million particles $\geq 0.5 \mu \mathrm{m}$ per minute (Martine and Verheyen, 2016).

\section{Ovum pick up}

Transvaginal oocyte retrieval (TVOR) technique is the process of collecting immature unfertilized oocyte directly from the ovaries of donor cow or heifer by using a specially designed probed equipped with an ultrasound transducer to visualize the ovary during oocyte aspiration (Pieterse et al., 1988). The compatibility of oocyte size ranges from 2-8 mm, (Abdullah et al., 2018). OPU sessions averaging 15 oocyte and 6 embryos per session of oocyte collection from live donor (Meiyu et al., 2013; Chowdhury et al., 2017)

Donor: Donor should be selected carefully. Outstanding donors are found in all the breeds. It is reported that oocytes retrieved through OPU per session is consistent with time but production of oocyte varies with individual animal. Bos taurus consistent in oocyte production even after 32 times retrieval (Petyim et al., 2003); Bos indicus decreases in oocyte retrieval with time (Gimenes et al., 2015). Certain factors are closely correlated with the long term production of oocyte through OPU. Anti-Mullerian hormone (AMH) level is directly correlated with number of population of oocyte present in the ovaries as well as correlated with oocyte retrieval through OPU. Higher the 
retrieval of oocyte higher the number of in vitro embryo production, (Boni et al., 1997; Baldrighi et al., 2014; Batista et al., 2014; Guerreiro et al., 2014; Monteiro et al., 2017). Oocyte production is repeatable trait for female animals (Boni et al., 1997; Ireland et al., 2007; Baruselli et al., 2015; Monteiro et al., 2017; Watanabe et al., 2017).

\section{Hormonal protocol OPU}

Administration of exogenous hormones leads to appearance of more number of follicles in the ovary at the time of oocyte collection through OPU. Subsequently, more number of oocytes retrieval and embryos production with minimal labour (Meiyu et al., 2013). It is reported that in once-a-week OPU procedure, the average number of follicles aspirated, oocytes retrieved and blastocysts produced on day 7 was significantly higher in a $\mathrm{FSH}$ treatment than non-stimulated OPU procedure per cow per session basis (Chaubal et al., 2007). By FSH treatment followed by OPU produces more number of Grade A oocytes than Grade C oocytes. In researches, it is concluded that oocytes yield per animal increased $(\mathrm{p}<0.05)$ in multiple FSH administration compared to single administration (Sendag et al., 2008). Also FSH treatment increases the quality of oocyte (Sendag et al., 2008). Administration of LH 6h prior to OPU, it is increased the number of blastocysts per OPU session (Chaubal et al., 2007; Sendag et al., 2008; Meiyu et al., 2013). In spite of all still has big window to left to scientists hand to do the improvement in the part of hormone-stimulated OPU.

\section{Factors affecting OPU}

1. Breed difference: Bos indicus breeds have more follicular waves, large pool of follicular reserve, contain more population of small follicles $(<5 \mathrm{~mm})$ at a time (Segerson et al.,1984; Figueiredo et al., 1997; Viana et al., 2000; Meiyu et al., 2013).

2. Nutrition and health: Enough amount of nutrition which maintains the proper health as well as it helps in the yield of good number of oocyte through OPU. It also plays role in embryo viability followed by successful pregnancy (Rubin et al., 2005; De et al., 2011; Watanabe et al., 2017).

3. Age: This technique helps to collect oocyte from heifer, adult cow, pregnant cow (De et al., 2011).

4. Heat stress: Less quantity and quality of oocyte observed during the period of summer while the number of follicles of 3$8 \mathrm{~mm}$ range of diameter per ovary was higher in winter. Recovery of oocyte in winter vs summer is ranges between 7.5 oocytes vs 5.0 oocytes per ovary (Zeron et al., 2001; Roth et al., 2002; Meiyu et al.,

\section{Practical benefits of OPU over ET}

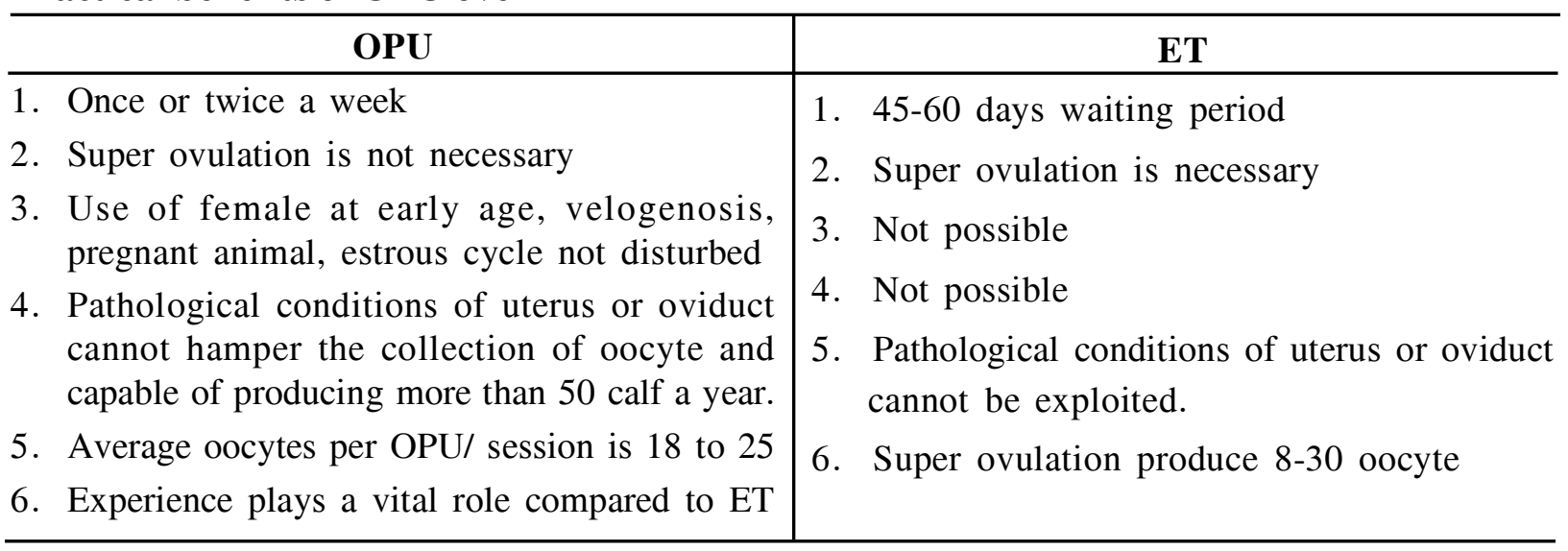

(Wagtendonk, 2000; Sirard et al., 2006; Van Wagtendonk-de, 2006; Rodriguez, 2011; Verma et al., 2012; Meiyu et al., 2013, Purohit, 2018) 
2013). Some author reported that bovine oocyte development was arrested in summer (Roth et al., 2002).

5. Operator's experience: To collect enough amount of oocyte need expertise hand and yields ranges from 0- 25 oocytes per session (Meiyu et al., 2013).

6. Individual variation: Variation among the donors persists in terms of production of oocyte in the ovary and followed by collection of oocyte by OPU procedure. The variation of response of the exogenous gonadotropin has observed among individuals (Meiyu et al., 2013).

7. Absence of dominant follicle (DF): Improved the blastocysts produced on day 7 (Gradela et al., 2000; Meiyu et al., 2013).

8. Animal: Heifers yield significantly higher number of total oocytes (4.7 vs. $2.8, \mathrm{P}<0.001$ ) and Grade A- B oocytes (3.0 vs. 1.8, $\mathrm{P}<0.05$ ) compared to cow (Rizosa et al., 2005). It is recorded that pregnant cows produce good quality blastocyst and freezable embryos than non-pregnant cows (Takuma et al., 2010; Meiyu et al., 2013). Both the technique can yield more than 50 calf a year.

\section{Increase in demand of OPU 2000- 2015}

In US, there is increased demand of OPU $(2,099$ to 32,636$), 29 \%$ to $53 \%$ while reduction in embryo flushes $39 \%$ to $30 \%$ (Moore and Hasler, 2017).

\section{Limitation of hormone treatment for OPU}

Long-term application of exogenous hormone causes disturbances in the donor endocrine system and having the capability to develop infertility to the animal. The response of the donor animal towards to hormone stimulation is varies with individual to individual leading to variation in the result (Meiyu et al., 2013). It is also found that ovarian response, appearance of number of follicles on ovaries and oocyte quality are affected by the type of gonadotropin used (Sendag et al., 2008). The best way to use the exogenous hormones in the donor is to apply short period followed by a resting period for normalization and recovery to the endocrine system (Meiyu et al., 2013).

\section{Constrains}

Oocytes collected from slaughter house ovarian samples shows sub-optimal maturation of COCs after OPU (Merton et al., 2003; Lonergan, 2007). OPU is applicable where slaughter house is unavailable. OPU is the one and only way to collect oocyte from live elite animal (Manik et al., 2003). Many instances observed low oocyte yield per session after continuous successive oocyte collection session (Machado et al., 2006). In vivo mature oocyte has greater competency than IVM oocyte. Species differences also a factor like, IVP efficiency in lower in buffalo compare to cattle (Rodriguez et al., 2012). Large calf syndrome, heavier birth weights, twining rate over $30 \%$ in cow, large ovary syndrome, higher rates abortion, extended gestation periods and increased rates of perinatal mortality observed (Lu et al., 1989; Hasler, 2000). Still research and improvement is going on throughout the world to minimize the all flaws of this technology.

\section{Future scope}

Greve and Madison (1991) has observed the potentiality of IVF technology and assumption of development this technology with development of OPU technique of oocyte collection. In India till this technology in grass root level. To standardize this technique, OPUIVF technique initially must be utilized in large farms in Indian sub continent. Once the results are coming at scientifically significant level than can starts dispense this technology to other small-scale farmers. To dispense this technology in the field, need extensive training to the technical people willing to acquire the technical knowledge at the field level followed by adaptation of this technology by the farmers itself. The trained people can select the best females from the population regards of their production and productivity. 
The extension work for this biotechnological tool to the enthusiastic farmer can lead to self-advertisement for this technology followed by adaptation of other farmers. The selection farmers and their satisfaction will give the best outcome of the technology. For the implementation of this technology in a wide range need Governmental and institutional help at all the level.

\section{Application of IVF}

IVF may perform like genetic 'insurance policy', when the outbreak of lethal diseases or for endangered species. IVP can salvage the irreversible genetic diseases which lead to culling. By this technique can generate embryo with known/fixed genomics, sex, date, donor and recipient and can produce more than 50 calves/ year (Hasler, 2003; Wrathall et al., 2004; Meiyu et al., 2013). IVF technology increases the genetic gain by reducing the generation interval. It is also contributing to produce embryos for research, purpose, embryonic stem cells (ESCs) (Gordon and Lu, 1990; Mapletoft and Hasler, 2005).

OPU-IVF maximizes the use of sexed semen, cloning, embryo sexing, analysis of pattern of gene expression, analysis of cytogenetic disorders and analysis of rapidly multiplying rare genes (Galli and Lazari, 2008; Verma et al., 2012). Increase scope in production of transgenic animal production by nuclear transfer technique and simultaneously production of recombinant medicine for human use (Blash et al., 2012). Combination of somatic cell banking and nuclear transfer technology can be used as a tool to conserve endangered breeds. Present days, there are increases in the production of transgenic animal after CRISPR/C as genome editing (Abdullah et al., 2018). This technique extensively used for commercial production of calf, especially beef breeds in Japan and Italy (Hamano et al., 2006). In total, due to extensive use of this technology for production of

\section{REFERENCES}

Abdullah K, Erdoðan G and Erdoðan M, 2018. Application of reproductive biotechnologies for experimental embryos leading to submission of more reports upon discoveries, findings about embryos in site like Pub Med. In this well known site there are recorded over 1000 publications related to bovine embryos from the year 2011 2014 (Meiyu et al., 2013; Parrish, 2014).

\section{Conclusions}

The future of IVF and OPU- IVF technology is very bright can generate more employment, can add most valuable animals to the population such as pure indigenous breed of animals, reconstructing the population of endangered animals. Being superior to the ETT, this technology has the power to provide and produce high number of superior sexed embryo with economical traits, disease resistance, thermo-tolerance, higher feed efficiency. Here can develop general recording system for selected animals produced by IVF method, which makes easy for progeny testing and genomic selection of animal. Application of this technology followed by dissemination of new and improved genetics will leads to increase in reproductive performance and it corresponding to increase in economic growth in livestock sector. There is a vast field open for research and application of the IVF and OPU-IVF in cattle as well as other domestic animals. Large ovary syndrome, high rates of abortion, extended gestation periods, large calf syndrome and increased rates of perinatal mortality are required for further studies which put emphasis on reduction in the incidences. The ssuccessful application of IVF and OPU-IVF may become a boon and boom for a country like India with huge population livestock is present.

Conflict of interest: Authors have no conflict of interest in this study.

Author contributions: All authors contributed equally to the manuscript.

sustainable production of livestock in Turkey.Turkish J Vet Anim Sci, 42: 143-151, doi: 
10.3906/vet-1706-66

Aggarwal BB, Quintanilha AT, Cammack R and Packer L, 1978. Damage to mitochondrial electron transport and energy coupling by visible light. Biochim Biophys Acta, 502(2): 367-82, doi: 10.1016/0005-2728(78)90057-9

Ayman M, Imran K, Kyeong-Lim L, Seok-Hwan S, Chowdhury MMR et al., 2017. 2Methoxystypandrone improves in vitro-produced bovine embryo quality through inhibition of IKBKB. Theriogenology, 99(1): 10-20, doi: 10.1016/j.theriogenology.2017.05.012

BAHS, 2019. Department of Animal Husbandry, Dairy and Fisheries, Govt. of India, New Delhi

Baruselli PS, Batista EOS, Vieira LM and Souza AH, 2015. Relationship between follicle population, AMH concentration and fertility in cattle. Anim Reprod, 12(3): 487-497

Batista EOS, Macedo GG, Sala RV, Ortolan MDDV, SáFilho MF et al., 2014. Plasma antimullerian hormone as a predictor of ovarian antral follicular population in Bos indicus (Nelore) and Bos taurus (Holstein) heifers. Reprod Domestic Anim, 49(3): 448-452, doi: 10.1111/rda.12304

Baldrighi JM, SáFilho MF, Batista EO, Lopes RN, Visintin JA et al., 2014. Anti-Mullerian hormone concentration and antral ovarian follicle population in Murrah heifers compared to Holstein and Gyr kept under the same management. Reprod Domest Anim, 49(6): 1015-1020, doi: 10.1111/rda. 12430

Blash S, Schofield M, Echelard Y and Gavin W, 2012. Update on the first cloned goats. Nat Biotechnol, 30: 229-230

Boni R, Roelofsen M, Pieterse M, Kogut J and Kruip T, 1997. Follicular dynamics, repeatability and predictability of follicular recruitment in cows undergoing repeated follicular puncture. Theriogenology, 48(2): 277-289, doi: 10.1016/ S0093-691X(97)84075-7

Boone R, Johnson JE, Locke A, Crane MM and Price TM, 1999. Control of air quality in an assisted reproductive technology laboratory. Fertil Steril, 71(1): 150-154, doi: 10.1016/S00150282(98)00395-1

Brackett BG, Bousquet D, Boice ML, Donawick WJ, Evans JF et al., 1982. Normal development following in vitro fertilization in the cow. Biol Reprod, 27(1): 147-158, doi: 10.1095/ biolreprod27.1.147

Casida LE, Meyer RK, McShan WH and Wisnicky, 1943. Effects of pituitary gonadotropins on the ovaries and the induction of super fecunity in cattle. Am J Vet Res, 4: 76-79

Cavalieria FL, Morotti F, Seneda MM, Colombo HB, Andreazzi MA et al., 2018. Improvement of bovine in vitro embryo production by ovarian follicular wave synchronization prior to ovum pick-up. Theriogenology, 117(1): 57-60, doi: 10.1016/j.theriogenology.2017.11.026

Chaubal SA, Ferre LB, Molina JA, Faber DC, Bols PE et al., 2007. Hormonal treatments for increasing the oocyte and embryo production in an OPU-IVP system. Theriogenology, 67(4): 719-728, doi: 10.1016/j.theriogenology.2006.07.022

Chowdhury MMR, Lianguang X, Rami K, Bun-Young $\mathrm{P}$, Ayman $\mathrm{M}$ et al., 2019. In vitro production of sex preselected cattle embryos using a monoclonal antibody raised against bull sperm epitopes. Anim Reprod Sci, 205: 156-164, doi: 10.1016/ j.anireprosci.2018.11.006

Chowdhury MMR, Choi BH, Khan I, Lee KL, Mesalam A et al., 2017. Supplementation of lycopene in maturation media improves bovine embryo quality in vitro. Theriogenology, 103: 173-184, doi: 10.1016/j.theriogenology.2017.08.003

CohenJ, Gilligan A, Esposito W, Schimmel T and Dale B, 1997. Ambient air and its potential effects on conception in vitro. Human Reprod, 12(8): 17421749, doi: 10.1093/humrep/12.8.1742

De LIG, Ayala A, Ake R and Gonzalez A, 2011. Effects of body condition change over oestrus, follicular development and ovulation rate in Pelibuey ewes under tropical conditions. Trop Subtrop Agroecosystems, 14(2021): 337-347

Dean EM, 2015. Air quality in the assisted reproduction laboratory: A mini-review. J Asst Reprod Genet, 32(7): 1019-1024, doi: 10.1007/ s10815-015-0535-X

Destaillats H, Spaulding RS and Charles MJ, 2002. Ambient air measurement of acrolein and other carbonyls at the Oakland-San Francisco Bay Bridge toll plaza. Environ Sci Technol, 36(10): 2227-2235, doi: 10.1021/es011394c

Figueiredo RA, Barros CM, Pinheiro OL and Soler JM, 1997. Ovarian follicular dynamics in Nelore breed (Bos indicus) cattle. Theriogenology, 47(8): 14891505, doi: 10.1016/S0093-691X(97)00156-8

Forman M, Polanski V, Gilligan A and Reiger D, 2004. Reduction in volatile organic compounds, adehydes, and particulate air contaminants in an IVF laboratory by centralized and standalone air filtration systems. Fertil Steril, 82(2): 324, doi: 10.1016/j.fertnstert.2004.07.877 
Galli C and Lazzari G, 2008. The manipulation of gametes and embryos in farm animals. Reprod Domestic Anim, 43(2): 1-7, doi: 10.1111/j.14390531.2008.01136. $\mathrm{x}$

Gimenes LU, Ferraz ML, Fantinato-Neto P, Chiaratti MR, Mesquita LG et al., 2015. The interval between the emergence of pharmacologically synchronized ovarian follicular waves and ovum pickup does not significantly affect in vitro embryo production in Bos indicus, Bos taurus, and Bubalus bubalis. Theriogenology, 83(3): 385-393, doi: 10.1016/j.theriogenology.2014.09.030

Gradela A, Esper CR, Matos SPM, Lanza JA, Deragon LAG et al., 2000. Dominant follicle removal by ultrasound guided transvaginal aspiration and superovulatory response in Nellore cows. Arquivo Brasileiro de MedicinaVeterinária e Zootecnia, 52(1): 53-58, doi: 10.1590/S0102-09352000000 100013

Greve T and Madison V, 1991. In vitro fertilization in cattle: A review. Reprod Nutr Dev, 31(2): 147-157

Gordon I and Lu KH, 1990. Production of embryos in vitro and its impact on livestock production. Theriogenology, 33(1): 77-87, doi: 10.1016/ 0093-691X(90)90599-O

Guerreiro BM, Batista EOS, Vieira LM, SáFilho MF, Rodrigues CA et al., 2014. Plasma anti-Mullerian hormone: An endocrine marker for in vitro embryo production from Bos taurus and Bos indicus donors. Dom Anim Endocrinol, 49: 96-104, doi: 10.1016/j.domaniend.2014.07.002

Hafez YM, 2015. Assisted Reproductive Technologies in Farm Animals. ICMALPS 2015, Alexandria University, Egypt, pp 91-118

Hall J, Gilligan A, Scchimmel T, Cecchi M and Cohen J et al., 1998. The origin, effects and control of air pollution in laboratories for human embryo culture. Human Reprod, 13(4): 146-155, doi: 10.1093/humrep/13.suppl_4.146

Halliwell B and Gutteridge JM, 1989. The Chemistry of oxygen radicals and other oxygen derived species. In: Halliwell B, Gutterdge JCM, editors. Free Radicals in Biology and Medicine. Oxford, UK: Oxford University Press, pp 22-85, doi: 10.1177/0748233793009001-203

Hamano S, Miyamura M, Tuchiya H, Watanabe Y, Sato A et al., 2006. Mass production of cattle from IVM, IVF, and IVP embryos in Japan. J Reprod Deve, 52: $77-85$

Hasler JF, 2003. The current status and future of commercial embryo transfer in cattle. Anim Reprod Sci, 79(3-4): 245-264, doi: 10.1016/S0378-
4320(03)00167-2

Rodriguez MH, 2011. Assisted Reproductive Techniques for Cattle Breeding in Developing Countries: A Critical Appraisal of Their Value and Limitations. Swedish Links Indonesia Symposia, 2010-2011, Chapter HRM-2011, doi: 10.1111/ j.1439-0531.2011.01961.x

Hirao Y and Yanagimachi R, 1978. Detrimental effect of visible light on meiosis of mammalian eggs in vitro. J Exp Zool, 206(3): 365-9, doi: 10.1002/ jez. 1402060308

Hockberger PE, Skimina TA, Centonze VE, Lavin C, Chu $\mathrm{S}$ et al., 1999. Activation of flavin-containing oxidases underlies light-induced production of $\mathrm{H}_{2} \mathrm{O}_{2}$ in mammalian cells. PNAS, 96(11): 62556260, doi: 10.1073/pnas.96.11.6255

Ireland JJ, Ward F, Jimenez-Krassel F, Ireland JLH, Smith GW et al., 2007. Follicle numbers are highly repeatable within individual animals but are inversely correlated with FSH concentrations and the proportion of good-quality embryos after ovarian stimulation in cattle. Human Reprod, 22(6): 1687-1695, doi: 10.1093/humrep/dem071

Hasler JF, 2000. In-vitro production of cattle embryos: problems with pregnancies and parturition. Human Reprod, 15(5): 47-58, doi: 10.1093/humrep/ 15.suppl_5.47

Johnson LA, 2000. Sexing mammalian sperm for production of offspring: The state-of-the-art. Anim Reprod Sci, 60-61: 93-107, doi: 10.1016/S03784320(00)00088-9

Kuwayama M, Hamano S, Kolkeda A and Matsukawa K, 1996. Large scale in vitro production of bovine embryos. Proc. 13th Int Congon Anim Reprod, 71 (Abstr.)

Ottosen LDM and Hindkjaer J, 2007. Light exposure of the ovum and preimplantation embryo during ART procedures. J Assist Reprod Genet, 24: 99103, doi: 10.1007/s10815-006-9081-x

Lazzari $\mathrm{G}$ and Galli C, 1996. In vitro embryo production and its application to cattle breeding. Proc 12th Scientific Meeting of the AETA, Lyon, pp 73-82

Lonergan P, 2007. State-the-art embryo technologies in cattle. Soc Reprod Fertil Suppl, 64: 315-325

Lu KH, MacDonnel HF and Gordon I, 1989. Birth of calves after in vitro maturation and fertilization of follicular oocytes. Theriogenology, 31(1): 222, doi: 10.1016/0093-691X(89)90630-4

Lu KH and Polge C, 1992. A summary of two years' results in large scale in vitro bovine embryo production. Proc $12^{\text {th }}$ Int Cong on Anim Reprod, 
The Hague, The Netherlands, 3, 1315-1317

Machado SA, Reichenbach HD, Weppert M, Wolf E and Gonçalves PBD, 2006. The variability of ovum pick-up response and in vitro embryo production from monozygotic twin cows. Theriogenology, 65(3): 573-583, doi: 10.1016/ j.theriogenology.2005.04.032

McEvoy JD, 1992. Alteration of the sex ratio. Anim Breed Abstr, 60: 97-111

Madan ML, Single SK, Jailkhani S and Ambroe JD, 1991. In vitro fertilization and birth of first ever IVF buffalo calf. In proc Third World Buffalo Congress, Varna, Bulgaria, 7: 11-17

Mapletoft RJ and Hasler JF, 2005. Assisted reproductive technologies in cattle: A review. Rev Sci Tech, 24(1): 393-403

Manik RS, Singla SK and Palta P, 2003. Collection of oocytes through transvaginal ultrasound-guided aspiration of follicles in an Indian breed of cattle. Anim Reprod Sci, 76(3-4): 155-161, doi: 10.1016/ S0378-4320(02)00241-5

Martine N and Greta V, 2016. Personnel practices in an IVF clean room facility: A Practical Guide Chapter- Cooper Surgical Fertility and Genomic Solutions. Clean Room Technology in ART Clinics, pp 194-201

Mayer JF, Nehchiri F, Weedon VM, Jones EL, Kalin HL et al., 1999. Prospective randomized crossover analysis of the impact of an IVF incubator air filtration system (CodaGen $\mathrm{X}$ ) on clinical pregnancy rates. Fertil Steril. 72(1): S4243

Meiyu Q, Yuchang Y, Hong M, Jiabo W, Xiaochuan Z et al., 2013.Transvaginal ultrasound-guided ovum pick-up (OPU) in Cattle. J Biomimetics Biomater Tissue Eng, 18(2): 1-3, doi: 10.4172/1662100X.1000118

Merton JS, de Roos AP, Mullaart E, de Ruigh L, Kaal et al., 2003. Factors affecting oocyte quality and quantity in commercial application of embryo technologies in the cattle breeding industry. Theriogenology, 59(2): 651-674, doi: 10.1016/ S0093-691X(02)01246-3

Monteiro FM, Batista EOS, Vieira LM, Bayeux BM, Accorsi M et al., 2017. Beef donor cows with high number of retrieved COC produce more in vitro embryos compared with cows with low number of COC after repeated ovum pick-up sessions. Theriogenology, 90: 54-58, doi: 10.1016/ j.theriogenology.2016.11.002

Moore SG and Hasler JF, 2017. A 100-year review: reproductive technologies in dairy science. J Dairy
Sci, 100(12): 10314-10331, doi: 10.3168/ jds.2017-13138

Nain S, Saha A, Swain AK and Majumdar AC, 2006. Present status of in-vitro production in buffaloes. The Haryana Vet, 45: 1-6

Parrish JJ, 2014. Bovine in vitro fertilization: In vitro oocyte maturation and sperm capacitation with heparin. Theriogenology, 81(1): 67-73, doi: 10.1016/j.theriogenology.2013.08.005

Parrish JJ, Susko-Parrish JL, Leibfried-Rutledge ML, Critser ES, Eyestone WH et al., 1986. Bovine in vitro fertilization with frozen-thawed semen. Theriogenology, 25(4): 591-600, doi: 10.1016/ 0093-691X(86)90143-3

Petyim S, Ba ge R, Hallap T, Bergqvist AS, RodriguezMartinez $\mathrm{H}$ et al., 2003. Two different schemes of twice-weekly ovum pick-up in dairy heifers: effect on oocyte recovery and ovarian function. Theriogenology, 60(1): 175-188, doi: 10.1016/ S0093-691X(02)01363-8

Pieterse M, Kappen K, Kruip TA and Taverne M, 1988. Aspiration of bovine oocytes during transvaginal ultrasound scanning of the ovaries. Theriogenology, 30(4): 751-762, doi: 10.1016/ 0093-691X(88)90310-X

Purohit GN, 2018. Reproductive biotechnologies in Indian cattle. J Vet Sci Res, 3(1): 149

Ramadan-Talib Z and Prebble J, 1978. Photosensitivity of respiration in Neurospora mitochondria. A protective role for carotenoid. Biochem J, 176(3): 767-775, doi: 10.1042/bj1760767

Reuben JM, Gabriel A, Bó PS, Baruselli AM, Roberto S et al., 2018. Evolution of knowledge on ovarian physiology and its contribution to the widespread application of reproductive biotechnologies in South American cattle. Anim Reprod, 15(1): 10031014, doi: 10.21451/1984-3143-AR2018-0007

Rizosa D, Burke L, Duffy P, Wade M, Mee JF et al., 2005. Comparisons between nulliparous heifers and cows as oocyte donors for embryo production in vitro. Theriogenology, 63(3): 939-949, doi: 10.1016/j.theriogenology.2004.05.008

Rodriguez-Osorio N, Urrego R, Cibelli J, Eilertsen K and Memili E, 2012. Reprogramming mammalian somatic cells. Theriogenology, 78(9): 1869-1886, doi: 10.1016/j.theriogenology.2012.05.030

Rosenkrans CF, Zeng GQ, McNamara GT, Schoff PK and First NL, 1993. Development of bovine embryos in vitro as affected by energy substrates. Biol Reprod, 49(3): 459-62, doi: 10.1095/ biolreprod49.3.459

Roth Z, Arav A, Braw-Tal R, Bor A and Wolfenson D, 
2002. Effect of treatment with follicle-stimulating hormone or bovine somatotropin on the quality of oocytes aspirated in the autumn from previously heat-stressed cows. J Dairy Sci, 85(6): 1398-1414, doi: $10.3168 / j d s . S 0022-0302(02) 74207-0$

Rubin KCP, PontesJHF, Nonato-Junior I, Ereno-Junior JC, Pansard H et al., 2005. Influência do grau de sangue Nelorenaprodução in vivo de oócitos. Acta Scientiae Veterinariae, 33: 183

Pontes JHF, Melo Sterzab FA, Bassoa AC, Ferreiraa CR, Sanchesa BV et al., 2011. Ovum pick up, in vitro embryo production, and pregnancy rates from a large-scale commercial program using Nelore cattle (Bos indicus) donors, Theriogenology, 75(9): 1640-1646, doi: 10.1016/j.theriogenology. 2010.12 .026

Saini N, Singh MK, Singh K, Manik R, Singla S et al., 2015. 'Holi': India's first cattle calf produced through Ovum pick-up - IVF technology-froman aged Sahiwal cattle. Indian J Anim Sci, 85(3): 244-246

Segerson EC, Hansen TR, Libby DW, Randel RD and Getz WR, 1984. Ovarian and uterine morphology and function in Angus and Brahman cows. J Anim Sci, 59(4): 1026-1046, doi: 10.2527/ jas1984.5941026x

Sendag S, Cetin Y, Alan M, Hadeler KG and Niemann $\mathrm{H}, 2008$. Effects of eCG and FSH on ovarian response, recovery rate and number and quality of oocytes obtained by ovum pick-up in Holstein cows. Anim Reprod Sci, 106(1-2): 208-214, doi: 10.1016/j.anireprosci.2008.01.007

Sinclair KD, Broadbent PJ and Dolman DF, 1995. In vitro produced embryos as a means of achieving pregnancy and improving productivity in beef cows. Anim Sci, 60(1): 55-64, doi: 10.1017/ S1357729800008134

Sirard MA, Richard F, Blondin P and Robert C, 2006. Contribution of the oocyte to embryo quality. Theriogenology, 65(1): 126-136, doi: 10.1016/ j.theriogenology.2005.09.020

Squirrell JM, Wokosin DL, White JG and Bavister BD, 1999. Long-term two photon flourescence imaging of mammalian embryos without compromising viability. Nat Biotechnol, 17(8): 763-767, doi: $10.1038 / 11698$

Takigawa T, Wang B, Saijo Y, Morimoto K, Nakayama $\mathrm{K}$ et al., 2010. Relationship between indoor chemical concentrations and subjective symptoms associated with sick building syndrome in newly built houses in Japan. Int Arch Occu Environ
Health, 83: 225-35, doi:10.1007/s00420-0090475-9

Takuma T, Sakai S, Ezoe D, Ichimaru H, Jinnouchi T et al., 2010. Effects of season and reproductive phase on the quality, quantity and developmental competence of oocytes aspirated Japanese Black cows. J Reprod Dev, 56(1): 55-59, doi: 10.1262/ jrd.09-071H

Uehera T and Yanagimachi R, 1976. Microsurgical injection of spermatozoa into hamster eggs with subsequent transformation of sperm nuclei into male pronuclei. Biol Reprod, 15(4): 467-470, doi: 10.1095/biolreprod15.4.467

Umaoka Y, Noda Y, Nakayama T, Narimoto K, Mori T et al., 1992. Effect of visual light in vitro on embryonic development in the hamster. Theriogenology, 38(6): 1045-1054, doi: 10.1016/ 0093-691X(92)90118-B

Van Wagtendonk-deLeeuw AM, 2006. Ovum pick up and in vitro production in the bovine after use in several generations: A 2005 status. Theriogenology, 65: 914-925, doi: 10.1016/ j.theriogenology.2005.09.007

Verma OP, Kumar R, Kumar A and Chand S, 2012. Assisted reproductive techniques in farm animal - from artificial insemination to nanobiotechnology. Vet World, 5(5): 301-310, doi: 10.5455/vetworld.2012.301-310

Verma PK, 2005. Ultrasound guided transvaginal follicular aspiration and in-vitro embryo production in Sahiwal cows. M.V.Sc. Thesis submitted to the G.B. Pant University of Agriculture \& Technology, Uttaranclial, India, http://krishikosh.egranth.ac.in/handle/1/ 5810136529 [2nd July, 2021]

Viana JHM, Ferreira AM, Sá WF and Camargo LSA. 2000. Follicular dynamics in zebu cattle. Pesq Agropec Bras, 35(12): 2501-2509, doi: 10.1590/ S0100-204X2000001200021

Viana JHM, Figueiredo ACS and Siqueira LGB, 2017. Brazilian embryo industry in context: pitfalls, lessons, and expectations for the future. Anim Reprod, 14(3): 476-481, doi: 10.21451/19843143-AR989

Wagtendonk-de Leeuw AM, Van Mullaart ER, de RAPW, Merton JS, Den DJHG et al., 2000. Effects of different reproduction techniques: AI, MOET or IVP, on health and welfare of bovine offspring. Theriogenology, 53(2): 575-597, doi: 10.1016/ S0093-691X(99)00259-9

Wrathall AE, Simmons HA, Bowles DJ and Jones S, 
2004. Biosecurity strategies for conserving valuable livestock genetic resources. Reprod Fertil Dev, 16(1-2): 103-112, doi: 10.10371/RD03083

Watanabe YF, Alexandre HS, Rodolf DM, Roberta MF, Emiliana OSB et al., 2017. Number of oocytes retrieved per donor during OPU and its relationship with in vitro embryo production and field fertility following embryo transfer. Anim Reprod, 14(3): 635-644, doi: 0.21451/1984-3143-AR1008

Wolf CA, Brass KE, Rubin MI, Pozzobon SE,
Mozzaquatro FD et al., 2008. The effect of sperm selection by Percoll or swim-up on the sex ratio of in vitro produced bovine embryos. Anim Reprod, 5(3): 110-115

Zeron Y, Ocheretny A, Kedar O, Borochov A, Sklan D et al., 2001. Seasonal changes in bovine fertility: relation to developmental competence of oocytes, membrane properties and fatty acid composition of follicles. Reproduction, 121(3): 447-454, doi: 10.1530/rep.0.1210447

Received-04.07.2021, Accepted - 27.10.2021, Published-01.12.2021

Section Editor: Prof. S. K. Nandi, Associate Editor 